\title{
Genotype by environment interaction for the interval from calving to first insemination with regard to calving month and geographic location in Holstein cows in Denmark and Sweden
}

\author{
Ahmed Ismael, ${ }^{\dagger} \dagger^{1}$ Erling Strandberg, $†$ Britt Berglund, $\dagger$ Morten Kargo, ${ }^{*} \ddagger$ Anders Fogh, $\ddagger$ and Peter Løvendahl ${ }^{*}$ \\ ${ }^{*}$ Center for Quantitative Genetics and Genomics, Department of Molecular Biology and Genetics, Aarhus University, PO Box 50, \\ DK-8830 Tjele, Denmark \\ †Department of Animal Breeding and Genetics, Swedish University of Agricultural Sciences, PO Box 7023, SE-750 07 Uppsala, Sweden \\ †Knowledge Center for Agriculture (SEGES), DK-8200 Aarhus N, Skejby, Denmark
}

\begin{abstract}
The objectives of this study were to investigate genotype by environment interaction effects, with environments defined as calving month and geographic location, on the interval from calving to first insemination (CFI) of Holstein cows in Denmark and Sweden. The data set included 811,285 records on CFI for first-parity cows from January 2010 to January 2014 housed in 7,458 herds. The longest mean CFI was 84.7 $\mathrm{d}$ for cows calving in April and the shortest was $76.3 \mathrm{~d}$ for cows calving in September. The longest mean CFI of $87.1 \mathrm{~d}$ was recorded at the northernmost location (LOC-8), whereas the shortest mean CFI of $73.5 \mathrm{~d}$ was recorded at the southernmost location (LOC-1). The multiple trait approach, in which CFI values in different calving months and different geographic locations were treated as different traits, was used to estimate the variance components and genetic correlations for CFI by using the average information (AI)-REML procedure in a bivariate sire model. Estimates of genetic variance and heritability were highest for January calvings and 3 times smaller for June calvings. Location 2 had the highest heritability and LOC- 8 the lowest, with heritability estimates decreasing from LOC-2 to LOC-8. Genetic correlations of CFI between calving months were weakest between cold months (December and January) and warm months (June, August, and September); the lowest estimate was found between January and September calvings. Genetic correlations of CFI between the different geographic locations were generally strong, and the weakest correlation was
\end{abstract}

\footnotetext{
Received December 25, 2015.

Accepted February 29, 2016.

${ }^{1}$ Corresponding author: ahmed.ismael@mbg.au.dk or ahmedismael sayed@gmail.com
}

between LOC-3 and LOC-8. These results indicate a genotype by environment interaction for CFI primarily regarding seasons described by calving months. The effect of geographic location was less important, mostly producing a scaling effect of CFI in different locations. We concluded that CFI is more sensitive to seasonal effects than geographic locations in Denmark and Sweden.

Key words: interval from calving to first insemination, female fertility, genotype by environment interaction, calving month, geographic location

\section{INTRODUCTION}

Reduced fertility of dairy cows has a great effect on the overall dairy cattle industry because it is a major reason for increased number of inseminations, higher veterinary costs, and culling of dairy cattle, all of which negatively affect profitability (De Vries, 2006). The global use of AI in the dairy industry raised concerns about reranking of sires across different environments as a consequence of genotype by environment $(\mathbf{G} \times$ E) interactions (Falconer and Mackay, 1996). Such effects also could be important for dairy farmers within a country, because farmers could choose those sires best suited to the local production environment (Kolmodin et al., 2002; Strandberg et al., 2009).

A $\mathrm{G} \times \mathrm{E}$ interaction exists when the capacity to alter the phenotype in response to changes in the environment differs among animals (Falconer and Mackay, 1996). The common ways to investigate the existence of a $\mathrm{G} \times \mathrm{E}$ interaction are to use a multiple trait approach or a reaction norm approach with a random regression model. The multiple trait approach can be used when the environment is divided into distinct classes and analyzed as different traits, and a genetic correlation significantly different from unity identifies the existence of a $\mathrm{G} \times \mathrm{E}$ interaction (Falconer, 1952; 
Falconer and Mackay, 1996). For example, the multiple across-country evaluation method considers each country as a different environment, and the correlation of the same trait expressed in different countries is estimated (Schaeffer, 1994). Reaction norm models have been used to describe effects that change over a continuous scale, and the genotype effect is modeled as a function of the environment, called the reaction norm, which results in heterogeneous variance components and heritability with the change of environment (Kolmodin et al., 2002; Schaeffer, 2004).

Fertility traits are heavily influenced by environmental factors such as seasons (or months) of calving and geographical region. For example, days open for cows calving in September were 50 d shorter than for March calvings in US Holsteins (Oseni et al., 2004). A similar effect on days open was found in Thai Holstein crossbreds, where cows calving in March remained open 40 d longer than cows calving in October (Boonkum et al., 2011). Sensitivity to seasonal effects on conception rates was also found by Huang et al. (2008), who reported that US Holstein cows in New York inseminated in March and April have 10\% higher conception rates than cows inseminated in May and June. Furthermore, modifying the environment to improve reproductive performance has been reported. For example, a shorter interval from calving to first estrus, fewer days open, shorter calving interval, and fewer AI services required per cow were achieved by exposing cows calving in winter and fall to supplementary light at night (Hansen and Hauser, 1984; Reksen et al., 1999). Sensitivity to geographic regions within a country was reported by Oseni et al. (2003), who found days open in the southeastern United States to be $18 \mathrm{~d}$ longer than in the southwest. Similarly, days open for Swedish Red and White cows in southern parts of Sweden was $10 \mathrm{~d}$ shorter than in the northern parts of Sweden (Kolmodin et al., 2004).

The effect of geographic regions on the genetic variation of fertility traits, expressed as different countries, is reported by using a multiple across-country evaluation. Heterogeneous genetic variance and heritability estimates of the interval from calving to first insemination (CFI), days open, and interval from first to last insemination were estimated between Canada, the United States, Spain, Belgium, Switzerland, Germany, Austria, and joint Nordic countries (Denmark, Finland, and Sweden); however, the estimated genetic correlations of the same trait in different countries did not significantly differ from unity (Nilforooshan et al., 2010). On the other hand, genetic correlations less than unity were found for age at first calving between Brazil and Colombia (Cerón-Muñoz et al., 2004). Within Australia, Haile-Mariam et al. (2008) studied the effect of geographic regions on CFI and calving interval in Holstein cows across 3 geographic regions using the multiple trait approach and found heterogeneity of heritability estimates. However, the estimated genetic correlations of the same traits in different regions were very high and close to unity. An effect of seasonal change on fertility, expressed as calving month, was reported by Oseni et al. (2004), who found heterogeneity of both genetic variance and heritability estimates of days open in US Holstein cows across calving months using the reaction norm model, with the highest genetic variance and heritability estimates obtained in March calvings and the lowest in September calvings. The lowest estimate of genetic correlation of 0.78 was found between summer and fall calvings, indicating small changes in the ranking of animals across different calving months. Another monthly pattern of variance components and heritability estimates of days open was reported in Thai Holstein crossbreds by Boonkum et al. (2011), where the highest values for genetic variance, residual variance, and heritability estimate were found for March calvings and the lowest for October calvings.

Calving to first insemination interval is an economically important trait in the Nordic total merit index because it measures the cow's ability to return to cyclic estrus after calving. Furthermore, the trait is also correlated with the cow's ability to conceive early following insemination and become pregnant. For example, Haile-Mariam et al. (2003) reported that cows with a shorter CFI have higher pregnancy rates, shorter calving intervals, and higher first insemination nonreturn rates. The estimated genetic correlations between CFI and pregnancy rate, calving interval, and first insemination nonreturn rate were $-0.84,0.55$, and -0.69 , respectively. Although the importance of CFI and the effect of seasonal change and geographic location on fertility traits are well documented in the literature, no studies have been conducted on the genetic variation and the $\mathrm{G} \times \mathrm{E}$ interaction due to seasons of calving and geographic location on CFI. The objectives of the current study were to investigate the changes of genetic parameters and the existence of $\mathrm{G} \times \mathrm{E}$ interactions for CFI in relationship to season (i.e., calving month) and geographical location in Holstein cows in Denmark and Sweden.

\section{MATERIALS AND METHODS}

\section{Design, Animals, and Data}

The fertility trait used in the present study was CFI. Calving months and geographic locations based on the north-south distance from the equator were treated as different traits using the multiple trait approach to estimate genetic parameters and genetic correlations. 
Table 1. Number of records in each month by location block, total number of cows, and total number of sires used in each month and geographic location of interval from calving to first insemination for 811,285 cows

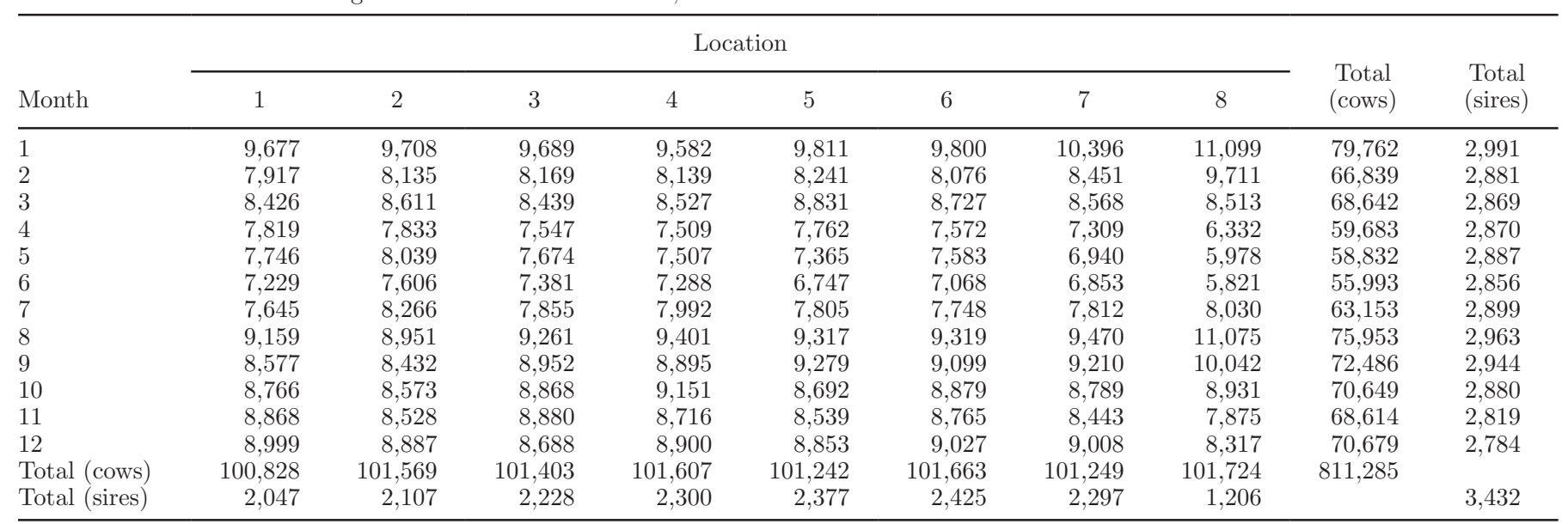

The insemination records for Holstein cows in Denmark and Sweden were obtained by the Nordic Cattle Genetic Evaluation NAV (SEGES, Aarhus, Denmark). Data were from first-parity Holstein cows that calved between January 2010 and January 2014. The raw data were edited using Nordic cattle genetic evaluation rules (NAV, 2013) by removing cows that moved to other herds during the insemination period or with age at first calving outside the range of 500 to 1,100 d. After calculating CFI, cows with CFI outside the range of 20 to $230 \mathrm{~d}$ were excluded from the analysis. From these records, only cows sired by bulls with at least 10 daughters were included in the analysis.

After editing, the final data set contained CFI records for 811,285 first-parity cows housed in 7,458 herds from 3,432 sires. The pedigree was built for use in a relationship matrix using a sire-dam structure and tracing back as many generations as possible in the Nordic Cattle database (NAV, Skejby, Denmark). The sire pedigree file included 23,089 animals.

\section{Seasonality and Geographic Location Classification}

Seasonality of CFI was defined by partitioning the data into 12 different parts based on the calving month and analyzed as different traits. The number of records of CFI in each calving month ranged from 55,993 (June calvings) to 79,762 (January calvings).

Geographic location classification was performed based on the postal codes and geographical positions of the herds. Postal codes of the herds were provided by SEGES and Växa (Uppsala, Sweden). The geographical positions were determined by the Universal Transverse Mercator coordinate system, in which the location was identified by 2 coordinates. The $x$ value indicates the east-west location, in kilometers, from the meridian line, and the $y$ value indicates the north-south location, in kilometers, from the equator. In our study, only the $y$ value was used to indicate the changes of CFI by geographic location because higher latitudes are associated with more extreme climatic conditions, including temperature and daylight length. Herds included in our study covered a distance from $6,060 \mathrm{~km}$ in southern Denmark to $7,507 \mathrm{~km}$ in northern Sweden. The data were sorted based on $y$ values before being assigned to 8 different locations, each containing $12.5 \%$ of the data set [location 1 (LOC-1) being southernmost to location 8 (LOC-8) being northernmost]. The number of records of CFI in each geographic location was approximately 101,400. Detailed summary of the number of cows in each month by location block and total number of cows and total number of sires used in each month and geographic location is shown in Table 1.

\section{Statistical Analysis}

The HPMIXED procedure in the SAS package (ver. 9.3; SAS Institute Inc., Cary, NC) was used to test for fixed effects in the model. Genetic analysis was performed with the AI-REML in the DMU package (Madsen and Jensen, 2010). Bivariate analyses were performed to estimate genetic correlations between the trait, expressed in different calving months or at different locations, to investigate for potential $\mathrm{G} \times \mathrm{E}$ interactions.

The first analysis fitted a univariate sire model to estimate variance components treating CFI in each calving month as different trait as follows:

$$
\mathrm{y}_{i j k l}=\mu+h_{i}+b(A G E)+l o c_{j}+s_{k}+\mathrm{e}_{i j k l},
$$


where $\mathrm{y}_{i j k l}$ is the trait value in a certain calving month for cow $l$ housed in herd $i$, located in geographic location $j ; \mu$ is the overall mean; $h_{i}$ is the fixed effect of herd $(i=1$ to 7,458$) ; b(A G E)$ is the fixed regression on age at first calving; $l o c_{j}$ is the fixed effect of geographic location class $(j=1$ to 8$) ; s_{k}$ is the random sire genetic effect, which was assumed to be normally distributed with distribution $\sim N D\left(0, \mathbf{A} \sigma_{s}^{2}\right)$, where $\sigma_{s}^{2}$ is the sire genetic variance and $\mathbf{A}$ is the sire additive genetic relationship matrix ( $k=1$ to 3,432 ); and $\mathrm{e}_{i j k l}$ is the random residual effect, which was assumed to be independently normally distributed with distribution $\sim \operatorname{IND}\left(0, \sigma_{e}^{2}\right)$.

The second analysis fitted a univariate sire model to estimate variance components treating CFI in each geographic location as different trait as follows:

$$
\mathrm{y}_{i j k l}=\mu+h_{i}+b(A G E)+m c_{j}+s_{k}+\mathrm{e}_{i j k l},
$$

where $\mathrm{y}_{i j k l}$ is the trait value in a certain geographic location for cow $l$ housed in herd $i$, calved in month $j$; $m c_{j}$ is the fixed effect of month of calving ( $j=1$ to 12 ); and all other factors are as in model 1.

The third analysis performed was an extension of models 1 and 2 to bivariate sire models to estimate genetic correlations for each trait between either the different calving months or the different geographic locations. The variance-covariance structure for this model is:

$$
\operatorname{Var}\left[\begin{array}{l}
s_{1} \\
s_{2}
\end{array}\right]=\left[\begin{array}{cc}
\mathbf{A} \sigma_{s_{1}}^{2} & \mathbf{A} \sigma_{s_{1} s_{2}} \\
\mathbf{A} \sigma_{s_{2} s_{1}} & \mathbf{A} \sigma_{s_{2}}^{2}
\end{array}\right],
$$

where $s_{1}$ and $s_{2}$ represent the sire effect of the cow in the first and second calving month or the first and second geographic location; $\mathbf{A}$ is the sire additive genetic relationship matrix as before; $\sigma_{s_{1}}^{2}$ and $\sigma_{s_{2}}^{2}$ are the sire genetic variances for the traits in different calving months or different geographic locations; and $\sigma_{s_{1} s_{2}}$ is the sire genetic covariance for the traits across calving months or geographic locations. Because the correlated traits are not recorded on the same animals, no environmental covariance exists between traits and the residual variance-covariance matrix is:

$$
\operatorname{Var}(e)=\mathbf{R}=\left[\begin{array}{cc}
\sigma_{e_{1}}^{2} & 0 \\
0 & \sigma_{e_{2}}^{2}
\end{array}\right],
$$

where $\mathbf{R}$ is the residual covariance matrix between traits, and $\sigma_{e_{1}}^{2}$ and $\sigma_{e_{2}}^{2}$ are the residual variances for the trait in different seasons. Genetic correlations are con- sidered significantly different from unity if they deviate by more than 1.645 standard error units from one, where the value 1.645 corresponds to a one-sided $5 \%$ cut-off point of the normal distribution.

\section{RESULTS}

In the present study, we used AI data from firstparity cows in Denmark and Sweden to study the effect of month of calving and geographical location on the phenotypic expression of CFI. Furthermore, we estimated the effect of month of calving and geographic location on the genetic parameters of CFI. Finally, we calculated genetic correlations between CFI expressed in different calving months and different locations to investigate possible $\mathrm{G} \times \mathrm{E}$ interactions.

\section{Phenotypic Effect of Month of Calving and Geographic Location on CFI}

Month of calving had a significant effect on CFI ( $P$ $<0.01$ ). The CFI was longest for April calvings, at $84.7 \mathrm{~d}$, and shortest for September calvings, at $76.3 \mathrm{~d}$ (Figure 1). Generally, summer and fall calvings had a shorter CFI compared with winter and spring calvings. The CFI was also affected by geographic location class $(P<0.01)$. The effect of geographic location on CFI is shown in Figure 2, where cows in LOC-1 (south) had the shortest CFI of $73.5 \mathrm{~d}$ and cows in LOC-8 (north) had the longest CFI of $87.1 \mathrm{~d}$.

\section{Variance Components and Heritability Estimates}

Figures 3 shows the sire genetic variance, residual variance, and the heritability estimates derived from the single trait analysis of CFI in each month of calving. The highest heritability estimate of 0.13 was associated

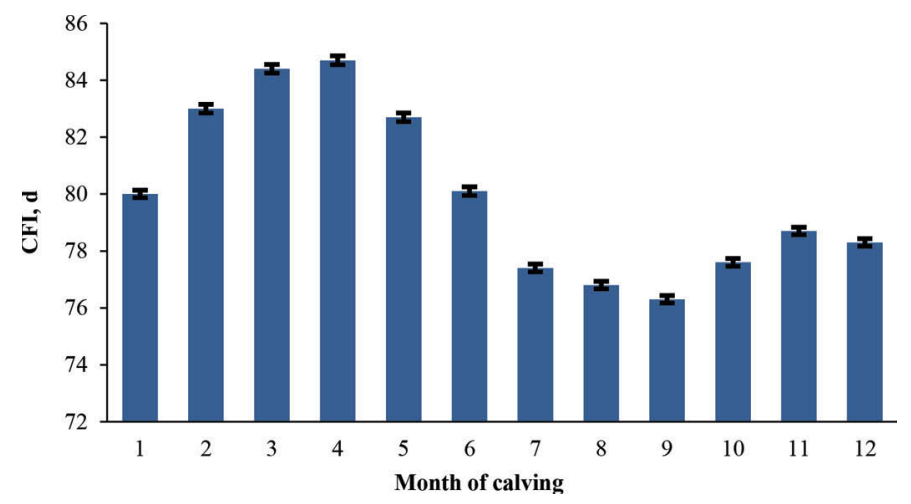

Figure 1. Effect of month of calving on the interval from calving to first insemination (means $\pm \mathrm{SE}$ ). $1=$ January to $12=$ December. CFI $=$ calving to first insemination. Color version available online. 


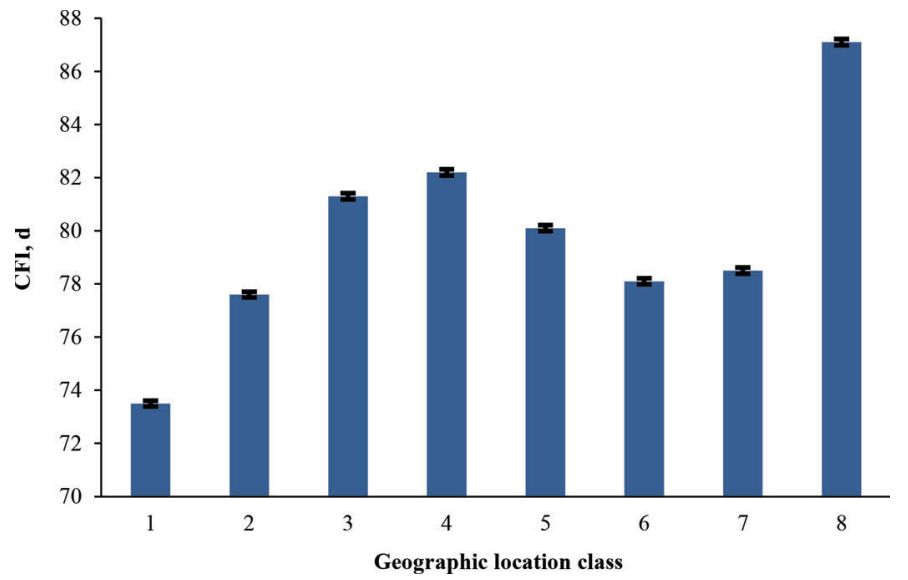

Figure 2. Effect of geographic location on the interval from calving to first insemination (means $\pm \mathrm{SE}$ ). $1=$ southernmost to $12=$ northernmost location. CFI $=$ calving to first insemination. Color version available online.

with the highest sire genetic variance for cows calving in January, and the lowest heritability estimate of 0.04 was associated with the lowest sire genetic variance for cows calving in June. The largest residual variance was found for March calvings, whereas the smallest residual variance was found for July calvings. The standard errors of the heritabilities were around 0.01 .

Figures 4 shows the sire genetic variance, residual variance, and heritability estimates derived from the single trait analysis of CFI in each geographical location. The highest heritability estimate of 0.10 was also associated with the largest sire genetic variance for cows in LOC-2, whereas the lowest heritability estimate of 0.05 was associated with the lowest sire genetic variance for cows in LOC-8. The highest residual variance was found for the cows in LOC-8, whereas the smallest residual variance was found in LOC-1. The standard errors of the heritabilities were 0.01 or less.

\section{Genetic Correlations of CFI in Different Calving- Month Classes or Geographic Locations}

The genetic correlations of CFI in different calving months are shown in Figure 5 as a heat map. The genetic correlations ranged between 0.64 and 1.00. Genetic correlations for CFI in different calving months were different from unity in 31 cases. The majority of the genetic correlation estimates found between winter months (December-February) and the remaining months were significantly less than unity, although the genetic correlations in most of the cases were above 0.85 . The lowest genetic correlation estimates were found between winter months (December-February) and spring and summer months (April, June, August,

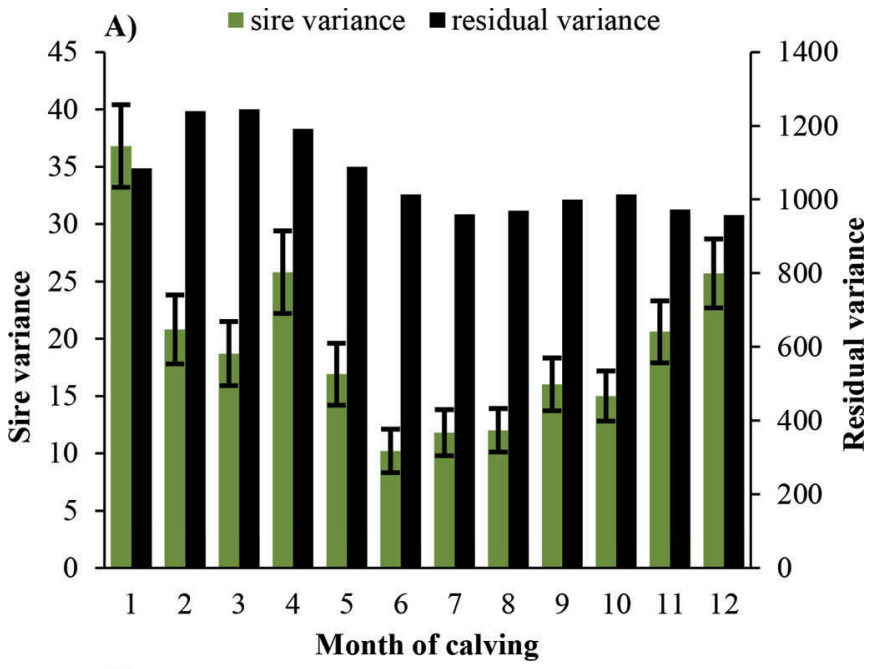

B)

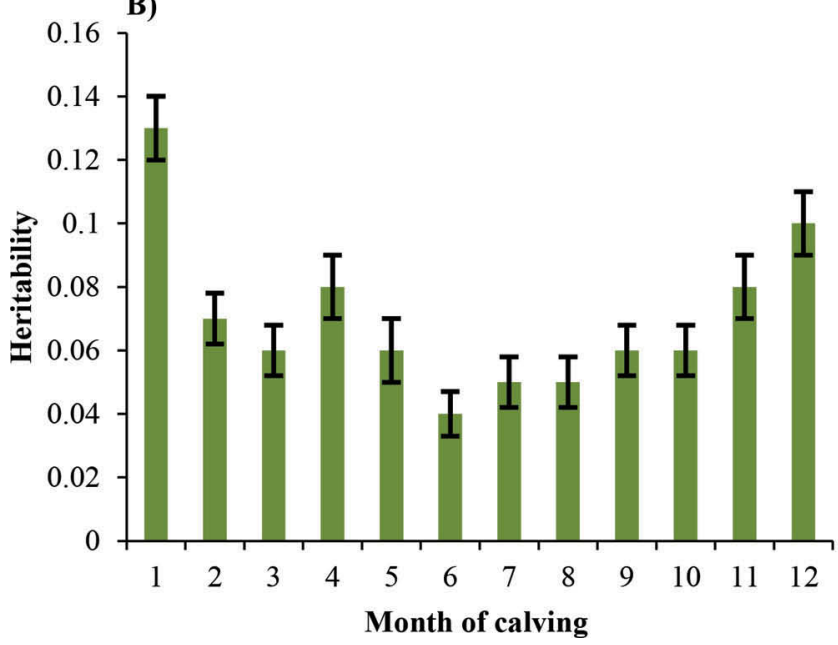

Figure 3. Heterogeneity of sire variance, residual variance, and heritability estimates (and their SE) for calving to first insemination (CFI) across calving months. $1=$ January to $12=$ December. Color version available online.

and September), and ranged between 0.64 and 0.84 , all different from unity.

The genetic correlations of CFI in different geographic locations are shown as a heat map in Figure 6. Genetic correlation estimates ranged between 0.80 and 1.00. The highest genetic correlations were found between all locations from LOC-1 to LOC-7, but lower genetic correlations were found between LOC- 8 and the other locations. The smallest genetic correlation of 0.80 was estimated between LOC-3 and LOC-8.

\section{DISCUSSION}

In the present study, we found month of calving and geographic location to have a significant effect on the phenotypic expression of CFI. Furthermore, the vari- 


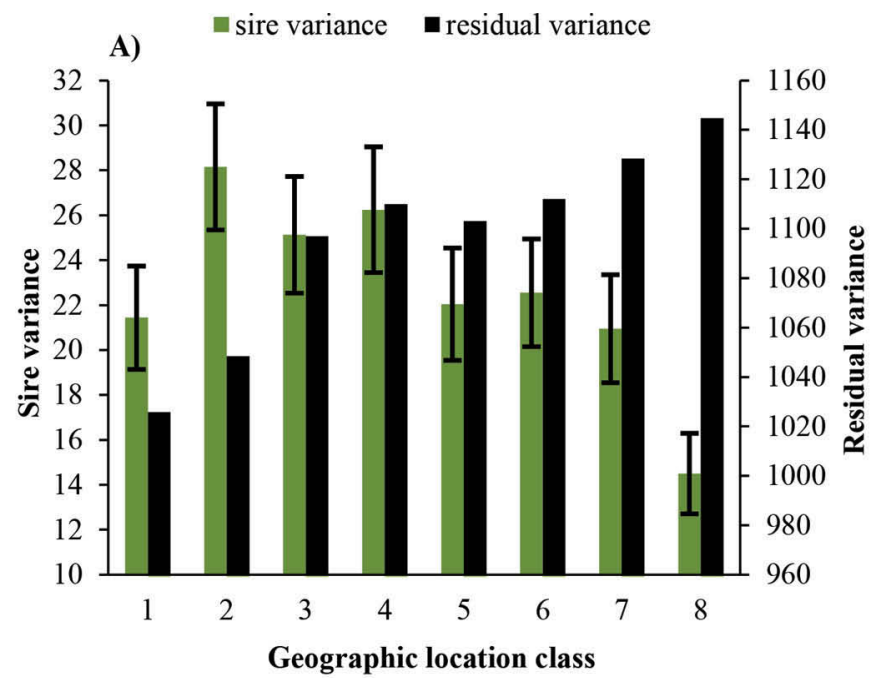

B)

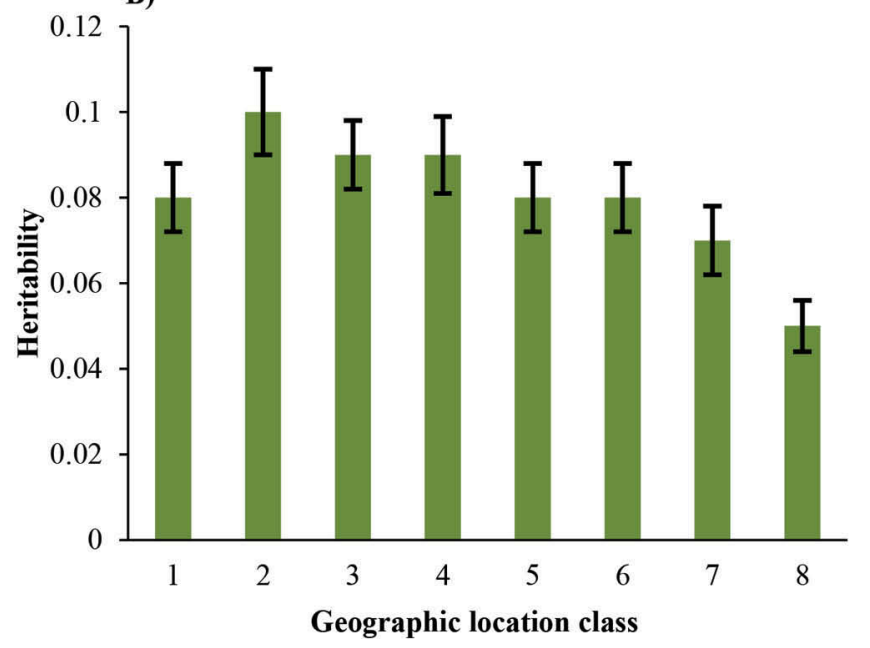

Figure 4. Heterogeneity of sire variance, residual variance, and heritability estimates (and their SE) for calving to first insemination (CFI) across geographic locations. $1=$ southernmost to $12=$ northernmost location. Color version available online.

ance components and heritability estimates for CFI were strongly influenced by month of calving and geographic location. The possible existence of a $\mathrm{G} \times \mathrm{E}$ interaction is supported by results of the estimates of genetic correlation between different calving months, but only to a small degree between different geographic locations.

\section{Effect of Month of Calving and Geographic Location on CFI}

Cows calving during colder months had a longer CFI compared with cows calving in warmer months. Cows calving in September had their first insemination 8 $\mathrm{d}$ earlier than those calving in April. Calving to first insemination interval showed an increasing trend from the lowest value in September $(76.3 \mathrm{~d})$ to the highest in April (84.7 d; Figure 1). The decrease in CFI from May to September was associated with increased daylight hours and temperature during the spring and summer seasons. On the other hand, the increase of CFI from October to January was associated with rapid decreases in daylight hours and temperature during the autumn and winter seasons. Previous studies have reported that, at the phenotypic level, fertility traits are influenced by seasonal components, including temperature and daylight length. For example, a pattern of monthly changes of CFI similar to what we observed in the present study was reported for days open in US Holstein cows in the southeastern United States, where March and April calvings were open $50 \mathrm{~d}$ longer than September calvings (Oseni et al., 2004). A similar effect of calving season was found in the ability of cows to return to cyclic estrus after calving by progesterone profiling (Petersson et al., 2007). Another example is the effect of calving season on the interval from calving to first high activity measured by activity tags, where summer calvers had their first high-activity episode 12 d earlier than spring calvers (Ismael et al., 2016). The trait was also found to be highly correlated with CFI (genetic correlation $=0.96$; Ismael et al., 2015). One possible explanation of the positive effect of summer season in the present results might be the aggregate effect of daylight length and temperature, because in Nordic countries a large difference exists in both daylight length and temperature between winter and summer (average $8 \mathrm{~h}$ of daylight in winter vs. $16 \mathrm{~h}$ of daylight in summer; average $0^{\circ} \mathrm{C}$ in winter vs. $16.0^{\circ} \mathrm{C}$ in summer). Another possible explanation relates to the directionality of the environmental gradients; that is, whether daylight length and temperature are increasing (January to June) or decreasing (July to December). Such an effect was reported by Ismael et al. (2016) on calving to first high activity, who observed that cows calving during the increasing daylight season (January to June) had their first high-activity episode an average of $8 \mathrm{~d}$ later than cows calving during the decreasing daylight season (July to December).

The effect of geographic location on CFI was clear between extreme environments, where cows that calved in the northernmost location class (LOC-8) had a CFI $13 \mathrm{~d}$ longer than cows that calved in the southernmost location class (LOC-1). One explanation for this difference is that the herd sizes in LOC-1 are much larger (185 cows) than those in LOC-8 (41 cows). Thus, we speculated that large dairy herds may be better managed in terms of the efficiency of heat detection using activity tags or pedometers to prompt AI services, which consequently leads to the shorter CFI in LOC-1. 
Another possible explanation might be related to the differences between the daylight lengths in winter and summer in the southernmost and the northernmost locations. For example, the average CFI for winter calvers in the northernmost location (shorter daylight length) was $15 \mathrm{~d}$ longer than the average CFI for winter calvers in the southernmost location (longer daylight length).

\section{Variance Components and Heritability Estimates}

We found that heritability and genetic variance of CFI were not constant across calving months. Generally, cold months were associated with high heritability estimates compared with warm months, with the highest heritability estimate obtained for January calvings.
This estimate was 3 times higher than the estimate for June calvings. It is clear that this highest heritability estimate was mainly due to the highest genetic variance for January calvings, which was also 3 times the genetic variance for the June calvings. These results indicate that the monthly variation in CFI has a genetic component. Our findings are in agreement with those of Oseni et al. (2004), who reported that, for days open in US Holstein cows, the genetic variance for winter calvings was 3 times the genetic variance for fall calvings, as determined by using the multiple trait approach; however, in their study, the highest heritability estimate was found for spring calving, mainly due to the spring season having the smallest residual variance compared with the other calving seasons. Oseni et al. (2004) and

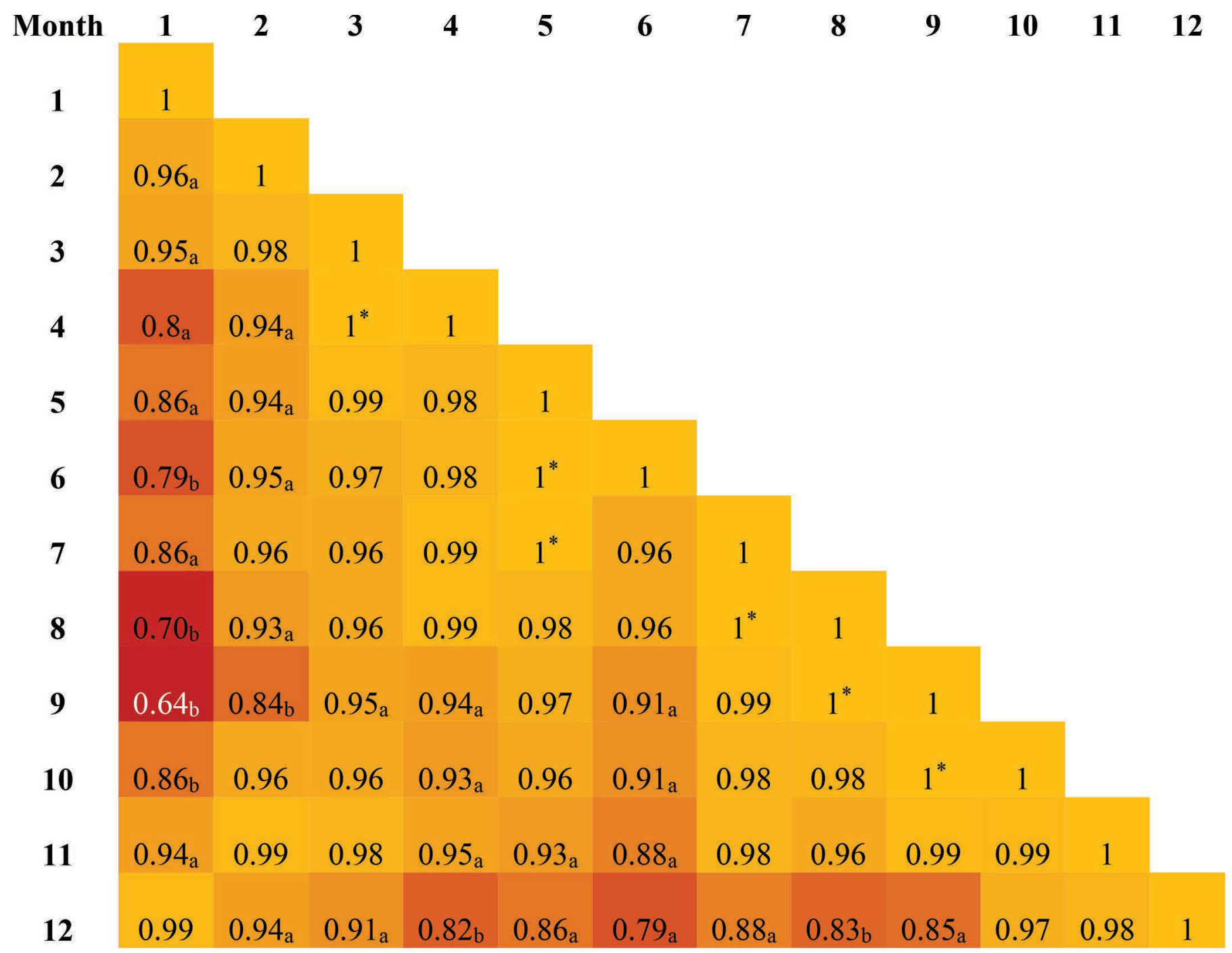

Figure 5. Genetic correlations of calving to first insemination (CFI) between different calving months. Subscript a means the value deviates

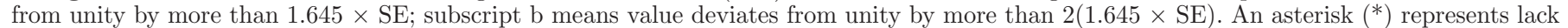
of convergence of the bivariate analysis because of a genetic correlation very close to unity. Color version available online. 


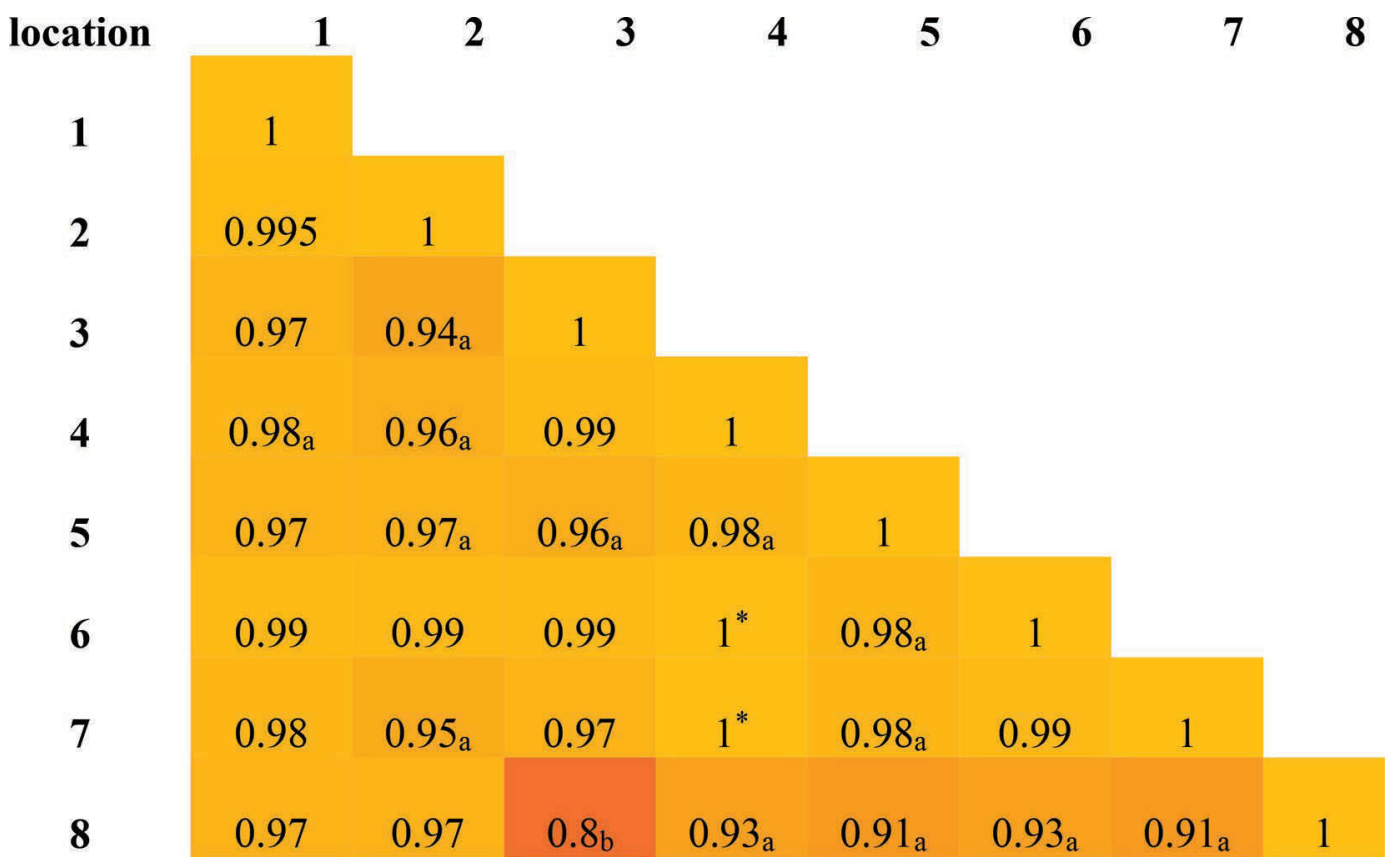

Figure 6. Genetic correlations of calving to first insemination (CFI) between different geographic locations. Subscript a means value deviates from unity by more than $1.645 \times \mathrm{SE}$; subscript b means value deviates from unity by more than $2(1.645 \times \mathrm{SE})$. An asterisk $(*)$ represents lack of convergence of the bivariate analysis because of a genetic correlation very close to unity. Color version available online.

Boonkum et al. (2011) used calving month to develop a heat index, which they used as a continuous environmental descriptor in the reaction norm model to model the genetic variation of days open across calving months in Holstein cows in the United States and Thailand, and found that the heritability of days open was heterogeneous across calving months: highest in March and lowest in September. The decrease of genetic variance and heritability estimates of CFI for summer calvings is in agreement with Ravagnolo and Misztal (2002), who observed low heritability estimates of nonreturn rate when the heat stress level were high using temperature humidity index as a continuous environmental descriptor in the reaction norm model in US Holsteins. Our results were in agreement with those of Ismael et al. (2016), who found that heritability of the interval from calving to first high activity (measured from activity tags) for winter calvings was 3 times higher than the heritability for spring and summer calvings

Heritability and genetic variance of CFI across different geographic locations were not constant. Heritability estimates decreased with increasing latitude, from LOC-2 to LOC-8, where the heritability estimate obtained for LOC-2 (the highest) was twice the heritability estimate found for LOC-8 (the lowest). The main reason for this difference is the genetic variance, which in LOC-2 was twice that in LOC-8. In contrast, residual variance increased with increasing latitude, where the lowest residual variance was found in LOC-1 and the highest in LOC-8. We found only one study estimated the genotype by geographic region interaction for fertility traits within the same country, where Haile-Mariam et al. (2008) reported heterogeneous heritability estimates for CFI across different geographic regions in Holstein cows in Australia where the heritability estimates ranged between 0.02 and 0.04 .

\section{Genetic Correlations of CFI in Different Calving Months and Geographic Locations}

Genetic correlations of CFI between different calving months were generally high. Between months within the same season, genetic correlation estimates were very strong compared with months in different seasons. Some of the genetic correlation estimates between months of the same season were different from unity, which means reranking of sires may exist if the birth months of daughters are unevenly distributed among months. Genetic correlations between months of the winter season on the one hand and months of the spring and summer seasons on the other had the lowest estimates of genetic correlations, where genetic correlations less than 0.80 were found between cold months (December and January) and warm months (June, August and September). This indicated a significant $G \times$ E interaction leading to a substantial reranking of sires 
between these months, but the reranking was greatest between the January and September calvings. Oseni et al. (2004) found a reranking effect due to a genetic correlation less than unity $\left(\mathrm{r}_{\mathrm{a}}=0.78\right)$ between summer and fall calving seasons in their study of days open in US Holstein cows. In that same study, those authors found a genetic correlation of 0.67 between the regular and heat stress effect due to months of calving using random regression of days open on the fixed solution of days open in different calving months. Furthermore, our research group found that the genetic correlation between warm and cold calving months for the interval from calving to first estrus was significantly less than unity $\left(r_{a}=0.46\right.$; Ismael et al., 2016).

One of the possible effects of the $\mathrm{G} \times \mathrm{E}$ interaction is the scaling effect due to the heterogeneity of genetic variances among different calving months; this means that, if the selection for superior individuals is performed in an average environment using the estimated breeding values, different selection responses in different environments should be expected (Falconer and Mackay, 1996). Furthermore, heterogeneity of heritability estimates across calving months will lead to different accuracies of selection of sires in different environments (Hill et al., 1983). However, notwithstanding the previous consequences of the heterogeneity of the genetic variances and heritability estimates, the superior sire in a single environment will remain superior in the other environments, and this effect could be accounted for by the correction of the estimated breeding values to an average environment (Meuwissen et al., 1996). On the other hand, reranking of animals across environments is more important than the scaling effect because it indicates that the best sire in a single environment is not the best across all environments (Falconer and Mackay, 1996). This means that selection of sires for a shorter $\mathrm{CFI}$ while ignoring the significant $\mathrm{G} \times \mathrm{E}$ interaction between these months would lower the rate of genetic progress (Robertson, 1959).

Genetic correlations of CFI between different geographic location classes were very strong and most of the estimates were close to unity, indicating that CFI is under the control of the same genes in different locations and the $\mathrm{G} \times \mathrm{E}$ interaction is less important and leads to only a scaling effect. Haile-Mariam et al. (2008) estimated the genetic correlation for CFI and calving interval between 3 geographic regions in Holstein cows in Australia and found that the genetic correlations ranged from 0.81 to 0.97 for the same trait in different regions. Therefore, sires from different locations in Denmark and Sweden could be used without concerns about the effect of a $\mathrm{G} \times \mathrm{E}$ interaction due to changing the geographic location.
One could respond to the obtained genetic correlation results of CFI between different calving months as follows: for the scaling effect due to the large heterogeneity of genetic variation between calving months or geographic location, the sire will remain at a similar ranking across environments but only differ in the magnitude of breeding values; adjustment of breeding values to the average environment in the genetic evaluation model should account for the scaling effect (Meuwissen et al., 1996). On the other hand, the reranking effect is more serious, which is the case between cold and warm months. Although we detected significant $\mathrm{G} \times \mathrm{E}$ interactions, they were mostly close to unity, and indications were for genotypes to rank more or less similarly under a wide range of calving months and geographic locations.

\section{CONCLUSIONS}

At the phenotypic level, CFI was affected by calving months, such that the performance is improved when calving occurs in the warm season. Genetic variances, residual variances, and heritability estimates were heterogeneous across calving months, but less so between geographic locations. Genetic correlations between geographic locations were mostly close to unity, indicating that sires are ranked more or less similarly under a this range of geographic locations in Denmark and Sweden. However, a clear genotype by environment interaction was noted between winter and spring or summer calving months.

\section{ACKNOWLEDGMENTS}

This study is a part of the project "Nordic research network on animal genetic resources in the adaptation to climate change," funded by the AnGR-NordicNET (NordGen, Nordic Council of Ministers, Ås, Norway). The authors also acknowledge the Knowledge Center for Agriculture (SEGES, Aarhus, Denmark) for providing the data. The first author is enrolled in the Erasmus-Mundus joint doctorate European Graduate School in Animal Breeding and Genetics "EGS-ABG" (Paris, France).

\section{REFERENCES}

Boonkum, W., I. Misztal, M. Duangjinda, V. Pattarajinda, S. Tumwasorn, and S. Buaban. 2011. Short communication: Genetic effects of heat stress on days open for Thai Holstein crossbreds. J. Dairy Sci. 94:1592-1596.

Cerón-Muñoz, M. F., H. Tonhati, C. N. Costa, J. Maldonado-Estrada, and D. Rojas-Sarmiento. 2004. Genotype $\times$ environment interaction for age at first calving in Brazilian and Colombian Holsteins. J. Dairy Sci. 87:2455-2458. 
De Vries, A. 2006. Determinants of the cost of days open in dairy cattle. Pages 1114-1115 in 11th International Symposium on Veterinary Epidemiology and Economics, Cairns, Australia.

Falconer, D. S. 1952. The problem of environment and selection. Am. Nat. 86:293-298.

Falconer, D. S., and T. F. C. Mackay. 1996. Introduction to Quantitative Genetics. 4th ed. Longman Group, Essex, UK.

Haile-Mariam, M., M. J. Carrick, and M. E. Goddard. 2008. Genotype by environment interaction for fertility, survival, and milk production traits in Australian dairy cattle. J. Dairy Sci. 91:4840-4853.

Haile-Mariam, M., J. M. Morton, and M. E. Goddard. 2003. Estimates of genetic parameters for fertility traits of Australian HolsteinFriesian cattle. Anim. Sci. 76:35-42.

Hansen, P. J., and E. R. Hauser. 1984. Photoperiodic alteration of postpartum reproductive function in suckled cows. Theriogenology 22:1-14.

Hill, W. G., M. R. Edwards, M.-K. A. Ahmed, and R. Thompson. 1983. Heritability of milk yield and composition at different levels and variability of production. Anim. Sci. 36:59-68.

Huang, C. S. Tsuruta, J. K. Bertrand, I. Misztal, T. J. Lawlor, and J. S. Clay. 2008. Environmental effects on conception rates of Holsteins in New York and Georgia. J. Dairy Sci. 91:818-825.

Ismael, A., E. Strandberg, B. Berglund, A. Fogh, and P. Løvendahl. 2016. Seasonality of fertility measured by physical activity traits in Holstein cows. J. Dairy Sci. 99. In press.

Ismael, A., E. Strandberg, M. Kargo, A. Fogh, and P. Løvendahl. 2015. Estrus traits derived from activity measurements are heritable and closely related to the time from calving to first insemination. J. Dairy Sci. 98:3470-3477.

Kolmodin, R., E. Strandberg, B. Danell, and H. Jorjani. 2004. Reaction norms for protein vield and days open in Swedish Red and White dairy cattle in relation to various environmental variables. Acta Agric. Scand. A Anim. Sci. 54:139-151.

Kolmodin, R., E. Strandberg, P. Madsen, J. Jensen, and H. Jorjani. 2002. Genotype by environment interaction in Nordic dairy cattle studied using reaction norms. Acta Agric. Scand. A Anim. Sci. $52: 11-24$
Madsen, P., and J. Jensen. 2010. A User's Guide to DMU, version 6, release 5. Aarhus University, Faculty of Agricultural Sciences, Denmark.

Meuwissen, T. H. E., G. De Jong, and B. Engel. 1996. Joint estimation of breeding values and heterogeneous variances of large data files. J. Dairy Sci. 79:310-316.

NAV. 2013. NAV Routine Genetic Evaluation of Dairy Cattle-Data and Genetic Models, 2nd ed. Accessed Mar. 31, 2016. http://www. nordicebv.info/wp-content/uploads/2015/04/General-description_ from-old-homepage_06052015.pdf.

Nilforooshan, M. A., J. H. Jakobsen, W. F. Fikse, B. Berglund, and H. Jorjani. 2010. Application of a multiple-trait, multiple-country genetic evaluation model for female fertility traits. J. Dairy Sci. 93:5977-5986.

Oseni, S., I. Misztal, S. Tsuruta, and R. Rekaya. 2003. Seasonality of days open in US Holsteins. J. Dairy Sci. 86:3718-3725.

Oseni, S., I. Misztal, S. Tsuruta, and R. Rekaya. 2004. Genetic components of days open under heat stress. J. Dairy Sci. 87:3022-3028.

Petersson, K. J., B. Berglund, E. Strandberg, H. Gustafsson, A. P. F. Flint, J. A. Woolliams, and M. D. Royal. 2007. Genetic analysis of postpartum measures of luteal activity in dairy cows. J. Dairy Sci. 90:427-434.

Ravagnolo, O., and I. Misztal. 2002. Effect of heat stress on nonreturn rate in Holstein cows: Genetic analyses. J. Dairy Sci. 85:3092-3100.

Reksen, O., A. Tverdal, K. Landsverk, E. Kommisrud, K. E. Boe, and E. Ropstad. 1999. Effects of photointensity and photoperiod on milk yield and reproductive performance of Norwegian red cattle. J. Dairy Sci. 82:810-816.

Robertson, A. 1959. The sampling variance of the genetic correlation coefficient. Biometrics 15:469-485.

Schaeffer, L. R. 1994. Multiple-country comparison of dairy sires. J. Dairy Sci. 77:2671-2678.

Schaeffer, L. R. 2004. Application of random regression models in animal breeding. Livest. Prod. Sci. 86:35-45.

Strandberg, E., S. Brotherstone, E. Wall, and M. P. Coffey. 2009. Genotype by environment interaction for first-lactation female fertility traits in UK dairy cattle. J. Dairy Sci. 92:3437-3446. 